\title{
El proceso electoral dominicano: difícil camino hacia la democracia
}

Pablo A. Mariñez

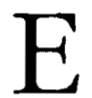

$\mathrm{n}$ las ültimas tres décadas en República Dominicana se han celebrado siete elecciones generales, a partir de las cuales se ha intentado, en un primer momento, permitir la transición hacia un régimen democrático $y$, posteriormente, consolidar dicho sistema. Sin embargo, el proceso ha sido sumamente complejo, pues la celebración de estas elecciones se ha visto entorpecida por fuerzas internas y externas en más de una ocasión.

En 1963, a los siete meses de haber asumido el gobiemo, el primer presidente elegido libremente en las últimas cuatro décadas fue derrocado por medio de un golpe militar; las segundas elecciones se realizaron en 1966, cuando el país se encontraba ocupado militarmente por tropas extranjeras; las terceras y cuartas elecciones, celebradas en 1970 y 1974 fueron muy cuestionadas por haberse desarrollado sin la concurrencia de los partidos de oposición; en 1978 el escrutinio de las elecciones del mismo año fue interrumpido violentamente por las fuerzas armadas, cuando el resultado comenzaba a arrojar un saldo desfavorable al partido oficial.

En el presente trabajo abordamos dos núcleos centrales de análisis. En el primero examinamos la permanente tensión política y social que se ha producido en el país en las últimas tres décadas entre lossectoressociales que han propugnado por la instauración de un sistema de- 
mocrático, donde lo socialy lo económico jugasen un lugar prioritario, y los que han querido reducir la democracia a su instancia político-electoral. En el segundo núcleo de análisis hacemos énfasis en las fuerzas políticas que han incidido en distintos niveles, en las diferentes elecciones celebradas.

\section{DEMOCRACIA ELECTORAL VERSUS DEMOCRACIA SOCIAL}

A raíz de la caída del régimen dictatorial de Rafael Leónidas Trujillo Molina, en mayo de 1961, en República Dominicana se produjo una coyuntura política favorable para la construcción de un sistema social democrático. Sin embargo, después de 31 años de una de las más férreas dictaduras de América Latina, diversos sectores (internos y externos) interpretaron que el camino más adecuado y correcto para la transición democrática era la celebración de elecciones libres. Por ello, todas las medidas tomadas por el Consejo de Estado que reemplazó la dictadura de Trujillo, ${ }^{1}$ tuvieron como eje central la política electoral. Desde ese momento en el país pasó a hacerse una homología entre democracia y elecciones. Esta homología implicaba, en los hechos,

${ }^{1}$ Cuando Trujillo fue asesinado el 30 de mayo de 1961, el presidente de la república era Joaquín Balaguer, quien ocupódicho cargo del 3 de agosto de 1960 al 31 de diciembre de 1961. El 1 de enero de 1962 se instala el Consejo de Estado, que después de ser reestructurado a mediados del mismo mes, gobierna hasta el 27 de febrerode 1963 , cuando Bosch asumió la presidencia de la república.

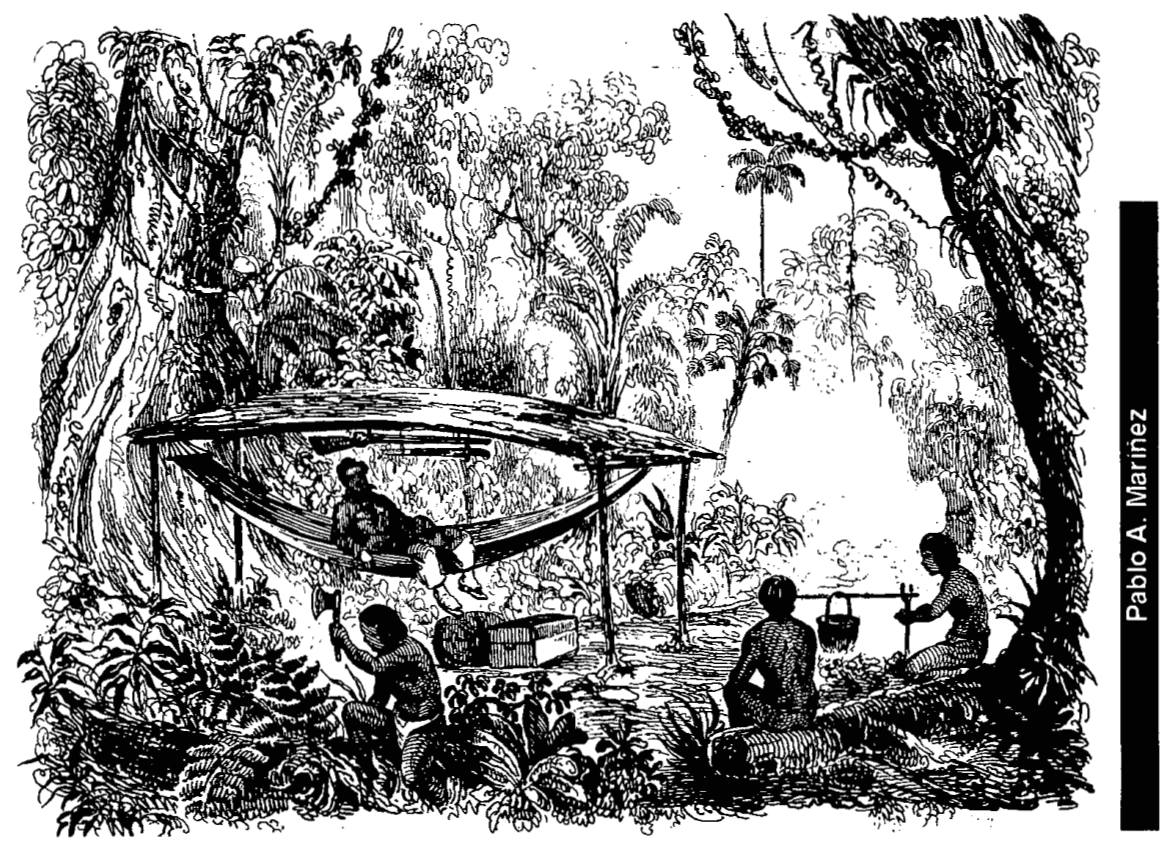


despojar la democracia de atributos que noson complementarios dela misma, sino sustanciales, como los de justicia social (solución de los problemas de desarrollo económico, del desempleo, del hambre $y$, en fin, de la miseria, así como los de salud y educación, entre otros), y el de la soberanía nacional. Es decir, la democracia planteada en República Dominicana quedaba limitada a su instancia políticoelectoral. En este contexto se puede comprender que en el corto plazo de 19 meses (junio de 1961 a diciembre de 1962) se hicieran los arreglos jurídicos y constitucionales necesarios que permitirian la realización de los comicios generales: elección de la Asamblea Constituyente que modificara la Constitución; nombramiento de la Junta Central Electoral; elaboración de una ley electoral que normara las elecciones; ley de amnistía general para que pudieran regresar al país los exiliados políticos; convocatoria de elecciones y desarrollo de la campaña electoral. Este conjunto de medidas en realidad se tomó en un tiempo menor al señalado, ya que Trujillo fue asesinado el 3 de mayo de 1961; pero toda la maquinaria del poder trujillista seguía intacta, por lo menos hasta finales del mismo año, cuando los hijos, hermanos y familiares másallegados del dictador abandonaron definitivamente el país. Además, el Consejo de Estado (integrado por siete civiles), en el que recayó la tarea de impulsar la política electoral, fue nombrado en enero de 1962. Por último los 19 meses señalados fueron de gran inestabilidad política y social, ya que se produjeron varios intentos de golpes y contragolpes deEstado, así como múltiples agitaciones sociales.

En sintesis, todo el esfuerzo del gobierno para que en el país se instaurara un régimen democrático se centró en la convocatoria y desarrollo de la jornada electoral. Por ello, a lo largo de esos 19 meses no se tomaron medidas significativas para modificar las estructuras económicas, políticas, sociales e institucionales en general, que permitieran organizar y consolidar un sistema social democrático.

La ley de reforma agraria promulgada en abril de 1962-y el agro constituía una de las áreas principales de la sociedad que demandaba una profunda reformano definía, en ninguno de sus capítulos, lo que se entendia por latifundio ni ponía limite a las grandes propiedades; tampoco se pronunciaba sobre la posesión de tierra por parte del capital extranjero. Hasta diciembre de 1962, fecha en que se celebraronlas elecciones presidenciales, sólo se hicieron cuatro asentamientos que beneficiaron a 863 parceleros con un total de 3848 hectáreas. En realidad, durante este periodo de gobierno fue más bien la oligarquía la que hizo su propia reforma agraria al apoderarse de las más importantes y ricas tierras que habían sido propiedad de la familia Trujillo. ${ }^{2}$ De ahí que el latifundio y las estructuras agrarias del país, bases de la dominación autoritaria, no fueron alteradas sino más bien reforzadas; de esta manera, la tradicional oligarquía dominicana, que había sido doblegada por Trujillo pero no aniquilada, se convirtió en la verdadera heredera del patrimonio agrariodominicano. En los hechos, era esta clase social la que estaba desplazando al dictador en el poder económico y político. Por otro lado, instituciones como las fuerzas armadas y la Iglesia católica, que tradicionalmente habían tenido un peso signifi-

\footnotetext{
${ }^{2}$ Pablo Marínez, "Luchas campesinas y reforma agraria en República Dominicana", en Historia politica de los campesinos latinoamericanos, Pablo González Casanova (coord.), Siglo XXI Editores, México, 1984, pp. 143-207.
} 
tivo en la vida política y social dominicana, seguían intactas a pesar de que eran renuentes a loscambios democráticos que propugnaban los sectores sociales más avanzados del país. Al respecto no podemos perder de vista que en el presente siglo los militares han ejercido el poder político, de una manera directa o indirecta, durante 56 años. ${ }^{3}$ La Iglesia católica, porsu parte, ha jugadoun papel nomenos significativo, primero por el apoyo brindado al gobierno dictatorial de Trujilloy, posteriormente, a raíz de la muerte de éste, por su alianza con los sectores más conservadores del país; incluso algunos miembros del alto clero han incursionado en la política nacional ocupando importantes cargos públicos, entre ellos el de miembro del Consejo de Estado, en 1962. Dentro de este contexto resulta explicable el rápido fracaso del experimento democrático en República Dominicana, aun tratándose de la instancia político-electoral.

En septiembre de 1963, a siete meses de haber asumido el gobierno merced a las primeras elecciones libres celebradas en más de cuatro décadas, Juan Bosch fue derrocado por un golpe de Estado militar. Para la consumación del mismo se aliaron tres fuerzas que tradicionalmente han gravitado con mucho peso en la política dominicana: la Iglesia católica, el imperialismo norteamericano y las fuerzas armadas. A Bosch sele acusó de querer instaurar el comunismo en el país, pero el verdadero motivo del golpe de Estado fue que el líder perredeísta intentó desarrollar un sistema democrático que trascendiera la instancia político-electoral. En su discurso de toma de posesión, el 27 de

\footnotetext{
${ }^{3}$ Maríñez, "Las fuerzas armadas en la República Dominicana: profesionalización y politización", El Caribe Contemporáneo, FCPS-UNAM, núm. 16, 1988, pp. 107-132.
}

febrero de 1963, Bosch manifestó lo siguiente: "solicitamos al Congreso nacional las leyes indispensables para afirmar en este país no sólo la democracia política, sino también la democracia económica y la justicia social". ${ }^{4} \mathrm{El}$ planteamiento de ningún modo se quedaba en lo retórico, sino que intentaba hacerse realidad. A los tres meses de que Bosch asumiera el poder se aprobó la Constitución más avanzada que haya tenido la República Dominicana en su historia. En ella se dejaban establecidas, muy clara y enfáticamente, las bases institucionales que permitirian la construcción de una sociedad democrática. Para que no hubiera duda al respecto, el artículo primero de la Carta Magna señalaba que las finalidades básicas de los poderes públicos del Estado eran: "proceder a la eliminación de los obstáculos de orden económico y social que limiten la igualdad y la libertad de los dominicanos y se opongan al desarrollo de la personalidad humana y a la efectiva participación de todos en la organización política, económica y social del país." Y en efecto, en sus 175 artículos restantes, la Constitución trazaba los principios fundamentales que permitieran hacer realidad el artículo primero antes señalado. 5

A la luz de los intereses de la oligarquía dominicana la aprobación de la

${ }^{4}$ Félix Jiménez, ¿Como fue el gobierno de Juan Bosch?, Ed. Alfa y Omega, Santo Domingo, 1988, p. 39.

${ }^{5}$ Dentro de los artículos de la Constitución se destacan los que plantean: $a$ ) la prohibición del latifundismo, b) que "solamente las personas fisicas dominicanas tienen derecho a adquirir la propiedad de la tierra", c) que la "libertad de creencias y de conciencia y la libertad de profesión religiosa e ideológica son inviolables", d) el derecho de todos los ciudadanos a "asociarse en partidos políticos", e) el derecho de los trabajadores a la huelga, etcétera. 
referida Constitución revelaba el carácter "comunista" del gobierno de Juan Bosch. Para alcanzar sus objetivos, la oligarquía utilizó, paradójicamente, las libertades democráticas que garantizaba el nuevo gobierno, con miras a desarrollar una amplia campaña para crear una opinión pública favorable al derrocamiento de Bosch. ${ }^{6}$ Tan pronto ello fue logrado, en septiembre de 1963, la Constitución fue derogada, las libertades públicas e individuales suprimidas, los dirigentes políticos, sindicales y estudiantiles, encarcelados odeportados; los partidos de izquierda, ilegalizados; los medios de comunicación, censurados, etc. A partir de ese momento se cerraban los espacios políticosinstitucionales para instaurar un régimen democrático en el país, por lo que no quedaba otro camino que el dela lucha armada. Por lo menos así lo entendieron los dirigentes de las principales organizaciones políticas, las que pasaron a operar desde la clandestinidado desde el exilio. El mismo día en que se produjo el golpe de Estado, el 25 de septiembre, un dirigente del Movimiento 14 de Junio señalaba lo siguiente: "Nos están azuzando, nos están provocando, y no tendremos otra alternativa que dar hasta nuestra última gota de sangre para ver desplazados del poder, a aquellos que

\footnotetext{
${ }^{6} \mathrm{El}$ documento que presenta la mejor prueba de los espacios democráticos utilizados por la oligarquia para desacreditar y conspirar contra el gobiemo es la colección de textos, reproducción de noticias periodísticas, comunicados de prensa, etc., recogidos paradójicamente por las mismas fuerzas golpistas, ccmo supuesta prueba de los errores del gobierno constitucional y, sobre todo del comunismo del que la oligarquía acusaba a Bosch; nos referimos al Libro Blanco de las Fuerzas Armadas $y$ de la Policía Nacional de la Repuiblica Dominicana. Estudios y pruebas documentales de las causas del Movimiento Reivindicador del 25 de septiembre de 1963, Editora del Caribe, Santo Domingo, 480 pp.
}

han usurpado la voluntad popular." $\mathrm{Y}$ ciertamente, dos meses después, en noviembre del mismo año, esa organización política abrió seis frentes guerrilleros en las montañas dominicanas, ${ }^{8}$ los que en pocas semanas estuvieron condenados al fracaso. 9 A mediados de 1964 Juan Bosch, que se había caracterizado como el abanderado de la institucionalidad democrática, aunque externando una crítica a los que habían intentado desarrollar una lucha guerrillera en la modalidad que más tarde sería conocida como "foquismo", también era partidario de restituir la constitucionalidad mediante métodos violentos. Bosch señalaba lo siguiente:

El lider de este momento nacional no puede ser un dirigente político sino el coronel que pueda lanzar soldados a la lucha. Por eso desde el primer día de mi exilio les expliqué a los compañeros que la única manera de restituir la constitucionalidad era a través de los soldados -los contados soldados capaces de luchar por un régimen de derecho-, pero no todo el mundo ve con claridad los fenómenos políticos y en nuestro país hubo gente que creyó que allí podía hacerse una revolución armada. Fueuna ilusión que dejó un saldode sangre muy lamentable. ${ }^{10}$

No por otra razón el Partido Revolucionario Dominicano, bajo el liderazgo

7 Tony Raful, Movimiento 14 de Junio, bistoria $y$ documentos, Ed. Alfa y Omega, Santo Domingo, 1983, p. 435.

${ }^{8}$ Fidelio Despradel, Manolo Tovarez Justo en su justa dimension bistorica. Las Manaclas, diario de la guerrilla, Ed. Alfa y Omega, Santo Domingo, 1983.

${ }^{\circ}$ Con anterioridad al levantamiento guerrillero del Movimiento 14 de Junio, el Movimiento Popular Dominicano-una organización política que se definía como marxista-leninista-intentóalzarse en las montañas, pero sus dirigentes fueron hechos prisioneros.

${ }^{10}$ Jiménez, op. cit., p. 430. 
de Bosch, se dedicó a conspirar con los militares, hasta que el 24 de abril de 1965 se produjo el estallido militarpara reponer la Constitución de 1963 y a Bosch en la presidencia de la república. Por ello el movimiento fue conocido como "Movimiento constitucionalista", y fue comandado precisamente por un grupo de coroneles, de los cuales Francisco Caamaño Deñó se destacó como el verdadero líder.

Ensíntesis, en el curso de los diez años siguientes al golpe de Estado de 1963, se produjeron por lo menos tres intentos importantes de levantarse en armas con miras a establecer un gobierno democrático, lo cual pone de manifiesto el rechazo que las organizaciones de izquierda y progresistas en general tenían por el sistema electoral como vía para acceder al poder. Estos tres intentos armados son los siguientes: el movimiento guerrillero llevado a cabo por el Movimiento 14 de Junio, bajo el liderazgo de Manolo Tavarez Justo, a finales de 1963; la insurrección cívico-militar de abril de 1965 al mando del coronel Caamaño Deñó; y en último lugar, la expedición armada e intento de desarrollar un frente guerrillero en las montañas dominicanas, también bajo el liderazgo deCaamaño, en febrero de 1973. ${ }^{11}$

Estos tres acontecimientos han marcado de una manera decisiva la vida política dominicana en las últimas décadas. Sin duda alguna el golpe militar de 1963 hizo que los líderes políticos dominicanos, y gran parte de la población perdieran confianza en el sistema electoral, y que incluso algunos de dichos líderes comenzaran a cuestionar la democracia formal o burguesa. En los meses

\footnotetext{
${ }^{11}$ Hamlet Hermann, Caracoles, la guerrilla de Caamaño, Ed. Alfa y Omega, Santo Domingo, 1980.
}

que transcurren entre el golpe de Estado y el estallido militar de abril de 1965, las organizaciones políticas se negaron rotundamente a participar en nuevas elecciones presidenciales que devolvieran el estado de derecho al país. La consigna proclamada: "vuelta a la constitucionalidad sin elecciones", logró un amplio respaldo popular.

El caso más destacado de cuestionamiento a la democracia formal y viraje ideológico de un líder político, fue el de Juan Bosch. En 1964, al escribir desde su exilio en Puerto Rico el libro Crisis de la democracia de América en la Repriblica Dominicana, Bosch señalaba lo siguiente:

Hay, pues, gente para construir la democracia en la República Dominicana. Pero antes de ponerse a levantar otra vez la casa de la libertad y de la justicia, esa gente mira hacia su pasado, mira hacia toda la América, y pregunta: "¿Vale la pena volver a edificar para que nos roben lo que hacemos? Rusia ayuda a Cuba, y a nosotros, ¿quién nos ayudará?"

Y la pregunta demanda una respuesta clara. Porque el problema no es si los dominicanos pueden o no pueden levantar de nuevo el hogar democrático; el problema es si todavía hay tiempo de hacerlo en un país americano agobiado por males de siglos. ${ }^{12}$

El intento de restituir la constitucionalidad mediante una acción militar fracasó a causa de la ocupación militar norteamericana de abril de 1965; por tal motivo Bosch radicalizanía su posición crítica contra la democracia formal o representativa, y contra el sistema norteameri-

${ }^{12}$ Juan Bosch, Crisis de la democracia de America en la Repüblica Dominicana, Centro de Estudios y Documentación Sociales, México, 1964 , p. 220. 
cano. En 1969 Bosch llegó a elaboraruna tesis de gobierno denominada Dictadura con respaldopopular, la cual gozó de amplia acogida en diversos sectores nacionales de la República Dominicana:

La dictadura con respaldo popular será un nuevo tipo de Estado que se dedicará a:

1. Garantizar trabajo, salud y educación a todos aquellos que actualmente no disfruten de esos atributos.

2. Garantizar absolutamente todas las libertades fundamentales del ser humano; la supresión del hambre y susfunestas consecuencias sociales; de la explotación de unos hombres por otros que tienen el dominio de los bienes de producción; del terror gubernamental, policial o de otra indole.

3. Garantizar la verdadera igualdad de todos los ciudadanos, no sólo antelasleyes del Estado sino también ante aquellas que no están escritas y sin embargo tienen divididos a los seres humanos por razones de raza, religión, estado social, cultura y sexo, y las quelanzan a luchar a unos contra otros para arrebatarse, o no dejarse arrebatar, la comida, la posición y los derechos. ${ }^{13}$

Después deeste planteamiento, hecho a la manera de principios programáticos, el autor pasa de inmediato a formular serias críticas a las limitaciones de la democracia representativa. Bosch señala lo siguiente:

La dictadura con respaldo popular no será la llamada democracia representativa, sistema político propio de la sociedad burguesa, que ha venido fracasando en la América Latina durante más de siglo y medio. No lo será, porque la democracia representativa, en el mejor de los casos, no puede garantizar trabajo, salud y cultura

${ }^{13}$ Bosch, Dictadura con respaldo popular, Publicaciones Max, Santo Domingo, 1971, p. 51. para todo el mundo; no puede garantizar las libertades fundamentales del ser humano y no puede garantizar su verdadera igualdad, dado que se trata de un sistema político y social fundamentalmente injusto, que se organiza y se sostiene sobre el principio de que hay hombres con derecho a explotara otros ylos hay con el deber de dejarse explotar. ${ }^{14}$

Cuando Bosch escribe la Dictadura con respaldo populardesde su exilio en Europa, en 1969, su pensamiento ya había comenzado a evolucionar hacia el marxismo. ${ }^{15}$ Gran parte de su producción intelectual durante esa época apunta precisamente a la demostración de la inviabilidad de la democracia representativa en el país, en tanto que, según Bosch, en República Dominicana no se había desarrollado la burguesía como clase social que sirviera de sustento a un régimen democrático representativo. ${ }^{16}$ Posiblemente también hayan sido los años más difíciles, en términos de credibilidad para la democracia formal y el sistema elec-

${ }^{14}$ Ibid., p. 52.

${ }^{15}$ Maríñez, "Evolución del pensamiento político de Juan Bosch" El Gallo Il ustrado, semanario de El Dia, núm. 1413, 23 de julio de 1989.

${ }^{16} \mathrm{El}$ libro Dictadura con respaldo popular, recoge diversos artículos que al respecto Bosch escribió durante 1969, pero el principal libro en este sentido es Composición social dominicana, escrito a mediados de 1968 en España y publicado en febrero de 1970 en Santo Domingo. Allí Bosch realiza un anális is histórico de Santo Domingo para demostrar el fracaso en la formación y desarrollo de una burguesía en el país. Esta tesis es la que le permitiría explicar (aunque no necesariamente en este mismolibro) el fracaso del sistema democrático. Bosch señala: "Del libro mismo se desprende que el pueblo dominicano no puede tener esperanzas de conocer un porvenir mejor que el pasado si no procede a cambiar el sistema en el cual ha venido fracasando casi durante 500 años. Para probar que ese sistema no funciona en Santo Domingo, con cinco siglos hay de sobra" p. 11. 
toral, en particular en el país. En esos años no se logró que los partidos deoposición concurrieran a las elecciones generales convocadas en 1970 y 1974 , lo cual implicaba un serio cuestionamiento a la legitimidad del partido en el gobierno, presidido por Joaquín Balaguer. No obstante ello, Balaguer -que había asumido la presidencia de la república con el apoyo de las tropas norteamericanas de ocupación, tras elecciones muy cuestionables en 1966-permaneció en el poder hasta 1978. Durante sus doce años de gobierno el mandatario dominicano se dedicó, por medio de los órganos represivos, policiales y parapoliciales, a eliminar a toda una generación de luchadores que propugnaban por un sistema democrático que trascendiera la instancia político-electoral. ${ }^{17}$ Cuando tal eliminación fue lograda y cuando además la correlación de fuerzas políticas se modificó -en parte por el vacio de liderazgo político que se había producidoy en parte por la derechización que había experimentado el PRD en los últimos años-, se produjo, en mayo de 1978, por primera vezenla década delossetenta, un proceso electoral competitivo, con gran participación de la población, que acudía a las urnas a darle su apoyo al PRD, pero fundamentalmente a votar en contra de la continuidad de Balaguer en la presidencia dela república. Unos años antes Bosch había renunciado al PRD, a causa de su derechización, para fundar una nueva organización, el Partido de la Liberación Dominicana (PLD), acorde con los nuevos lineamientos políticos de Bosch. ${ }^{18}$ Sin

\footnotetext{
${ }^{17}$ Mariñez, "República Dominicana: veinte años después de la intervención norteamericana de 1965", El Caribe Contemporáneo, FCPS-UNAM, núm. 11, 1985, México, pp. 61-91.

${ }^{18}$ Bosch, El PLD. Un partido nuevo en América, Ed. Alfa y Omega, Santo Domingo, 1989.
}

embargo, aunque el PRD se había derechizado continuaba con su discurso populista, enarbolando la bandera del cambio social y de la lucha contra la corrupción administrativa. En fin, lo cierto es que el PRDde 1978 distaba mucho de ser el de 1963, cuando se produjo el golpe militar, o de ser el PRD de 1965, cuando se produjo la ocupación norteamericana. Susprincipales líderes habían buscado el apoyo de los denominados sectores liberales de Estados Unidos, o se habían afiliado a la Internacional Socialista, con el fin de tener un respaldo externo que les permitiera, en caso de lograr presentarse a unas elecciones y triunfar, que dicha victoria les fuera reconocida. Para conseguir esto último el PRD tuvo que abdicar de su compromiso de instaurar un sistema democrático donde lo económico y social fuera prioritario, en favor de un sistema democrático donde la políica electoral jugara el papel básico. Por ello, cuando los militares balagueristas se oponen a reconocer el triunfo electoral del PRD en 1978, la Internacional Socialista y el gobiemo norteamericano, a través del Departamento de Estado y del Pentágono, ejercieron una seria presión contra Balaguer para que respetara el sufragio electoral. Washington sabía perfectamente bien que el PRD de 1978 no se propondría incursionar en los niveles sociales y económicos de la democracia. En fin, que el PRD de 1978 no iba a poner en juego sus intereses en el país y en la región en su conjunto.

Ello explica que rápidamente comenzara a manifestarse un fuerte descontento popular ante el gobierno del PRD. Sólo durante 1980 y 1981 se produjeron no menos de 87 huelgas, 18 tomas de locales y 35 manifestaciones o marchas de protesta, que arrojaron un saldo de 1289 detenidos y de 484 heridos. Estos conflictos de alguna manera eran la respuesta 
directa al número de cancelaciones de trabajadores que llegó a 3177 en 1980 y 2946 en 1981, así como a la agudización de la crisis económica que ya comenzaba a experimentarse. En el sector campesino el descontento no era menor pues en 1980 se produjeron 21 invasiones campesinas de tierra, que movilizaron a 1601 campesinos, los que ocuparon un total de 1991 hectáreas. En 19811863 campesinos, en diferentes regiones del país ocuparon un total de 4052 hectáreas de tierra gracias a trece invasiones. ${ }^{19}$

Ante el amplio deterioro de la base de sustentación social que comenzaba a producirse, el PRD recurrió a la estratagema de manejar la imagen de que el gobíernc de Antonio Guzmán no era el gobierno del PRD, lo que le permitía articular, desde dentro del mismo partido, una especie de "oposición", capaz de captar el descontento popular que le permitiera lograr nuevamente el apoyo electoral de la población. Y ciertamente, la pugna existente entre dos facciones del PRD (una gubernamental, muy conservadora, y aliada a los intereses de la oligarquía, la burguesía y el capital transnacional, y la otra, excluida del gobierno, que se identificaba con la Internacional Socialista) posibilitó que se presentara como una reserva política capaz de responder a las demandas de las grandes mayorias nacionales de instaurar un sistema democrático que incursionara en lo económico y en lo social. Este hecho le daba al PRD la categoría de ser el partido del "cambio", como se manejó en la campaña electoral de 1978 y 1982. Justamente por elloes que el "Programa degobierno"

\footnotetext{
${ }^{19}$ Estos datos han sido tomados de un trabajo inédito del autor escrito en 1983, titulado República Dominicana, 1978-1982: ¿Un proyecto socialdemócrata? Evaluación de los cuatro años de gobierno del Partido Revolucionario Dominicano.
}

de Salvador Jorge Blanco para las elecciones de 1982 planteaba que el PRD brindaria la "democracia económica", con lo que quería distanciarse del gobierno de Antonio Guzmán (1978-82), del cual se decía que sólo había ofrecido la "democracia política". Este recurso permite al PRD presentarse nuevamente como abanderado de la "democracia social" ante el Partido Reformista (PR) de Balaguer, típico representante de la "democracia formal". De ahí que todavía en las elecciones de 1982 la polaridad bipartidista continuara manifestándose como una constante del proceso electoral dominicano, cuando en realidad desde el punto de vista programático el PRD y el PR no presentaban diferencias sustanciales.

Una vez que Salvador Jorge Blanco llegó a la presidencia en 1982, la intensificación de la crisis económica y el apego de su gobierno a las medidas del FMI para tratar de darle solución a dicha crisis, generó un serio descontento popular, mayor al que había tenido que enfrentar Antonio Guzmán. Es por ello que en abril de 1984 Jorge Blanco tuvo que enfrentar el mayor estallido de protesta popularque haya conocido el país en losúltimos años. En dicho estallido murieron más de 100 personas a manos de la policía nacional $y$ las fuerzas armadas. ${ }^{20}$

Si a la incapacidad de responder a las demandas populares agregamos las pugnas de facciones que sufría el PRD, así como la corrupción administrativa en que incurría el equipo de su gobierno, se podría comprender mejor la decisión popular de expresar su rechazo al PRD en las elecciones de mayo de 1986, aunque fuese para volver a favorecer a Joaquín

\footnotetext{
${ }^{20}$ Mariñez, "República dominicana entre la lucha popular y la presión del FMI", El Caribe Contemporáneo, FCPS-UNAM, núm. 10, 1985, México, pp. 23-43.
} 


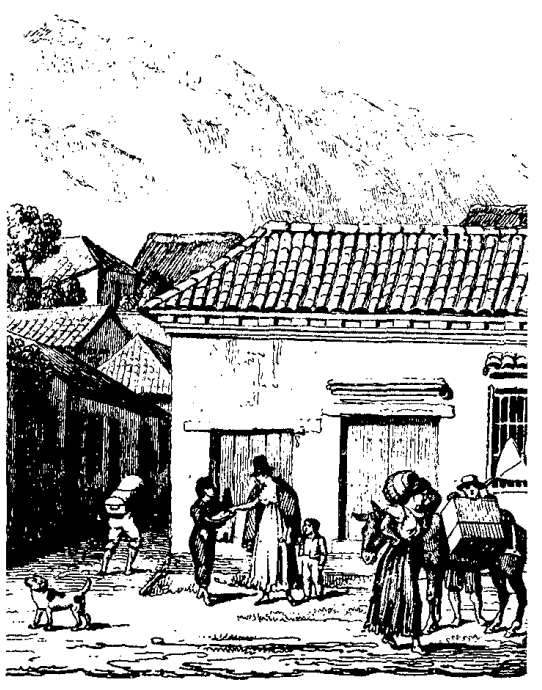

Balaguer. En realidad en mayo de $1986 \mathrm{el}$ electorado dominicano había quedado atrapado en las redes de la "democracia de las urnas", sin alternativa posible de cambio social, sin opción política capaz de triunfar electoralmente y alcanzar el poder. Justamente por esta situación las elecciones de 1986 marcan el inicio de un resquebrajamiento de la polarización bipartidista, donde el Partido de la Liberación Dominicana (PLD) logra alcanzar 18.9 de la votación con dos senadores y 16 diputados en el Congreso, cifras sin precedentes en el proceso electoral dominicano alcanzadas por un partido con las características del PLD.

En síntesis, podemos plantear que el periodo transcurrido desde la muerte de Trujillo, en mayo de 1961, hasta la actualidad se ha caracterizado por una permanente lucha política y social, donde los sectores populares han propugnado, sin conseguirlo, por la instauración de un sistema democrático de contenido social, en tanto que los sectores de la oligarquía y la burguesía han logrado imponer la versión de la democracia formal. Para lograr este objetivo la oligarquía dominicana ha tenido que aliarse a los intereses norteamericanos, así como recurrir a las fuerzas armadasy a la Iglesia católica para que incursionen en la vida política dominicana. Tratemos de explicar, aunque muy sucintamente, cómo se ha desarrollado esta triple injerencia en la política electoral del país.

\section{INJERENCIA NORTEAMERICANA, MILITAR Y RELIGIOSA EN EL PROCESO ELECTORAL}

Las primeras elecciones libres en República Dominicana, después de más de cuatro décadas, se celebraron en diciembre de 1962, justamente cuatro años después del triunfo de la revolución cubana de 1959 y veinte meses después de que la misma se declarara socialista, en abril de 1961. Este acontecimiento es sumamente significativo para poder comprender la dinámica de las fuerzas políticas y sociales, internas y externas, que participaron y se movieron alrededor de dichas elecciones. Señalemos los siguientes aspectos: a) con la revolución cubana se inició una "etapa de revolución social" en la región del Caribe, a la vez que se aceleró el proceso de descolonización; b) el mismo asesinato de Trujillo, en mayo de 1961, no se puede comprender si se hace abstracción de los acontecimientos que se habían iniciado en el Caribe en la misma década de los sesenta; ${ }^{21} c$ ) en 1959 se produjo una expedición armada de exiliados antitruji-

${ }^{21}$ Víctor Grimaldi, Los Estados Unidos en el derrocamiento de Trujillo, Imp. Amigo del Hogar, Santo Domingo, 1985. 
llistas que partió de Cuba en junio del mismo año y, aunque fracasó, tuvo un efecto importante en la política dominicana ${ }^{22} d$ ) a raíz del triunfo de la revolución cubana Estados Unidos modifica su. doctrina de seguridad hemisférica, sobreentendiéndose que el llamado "enemigo externo" también existía internamente, por lo que había que proteger las "fronteras ideológicas"; e) a la luz del nuevo contexto, los estrategas norteamericanos manifestaron un profundo temor de que surgieran "nuevas Cubas", particularmente en el área del Caribe, lo cual los llevaria a tratar de corregir mecánicamente los supuestos errores que habian cometido en Cuba y que habían permitido el triunfo de la revolución; $f$ ) por cuestiones de cercanía, afinidad y estrechas relaciones entre Cuba y República Dominicana, después de enero de 1959 llegaron a este último paîs centenares de cubanos exiliados que comenzaron a influir en la ideología dominicana; $g$ ) estos exiliados influyeron particularmente en dosinstituciones dominicanas: la Iglesia católica y las fuerzas armadas. El enfrentamiento que la revolución tuvo que librar contra el clero conservador en Cuba, dio lugar a que se manejara una fuerte propaganda sobre el supuesto carácter anticlerical de la revolución. Por tal razón el clero dominicano captó mecánicamente que de producirse una "nueva Cuba" en República Dominicana, el anticlericalismo sería una de sus características; de ahí su anticomunismo militante, que se expresaría de manera particular en la política electoral. En lasfuerzas armadas dominicanas, a su vez, el efecto fue mayor, por el desenlace a

${ }^{22}$ Juan Deláncer, Primavera 1979. Constanza, Maimón, Estero Hondo, Imp. Amigo del Hogar, Santo Domingo, 1979.

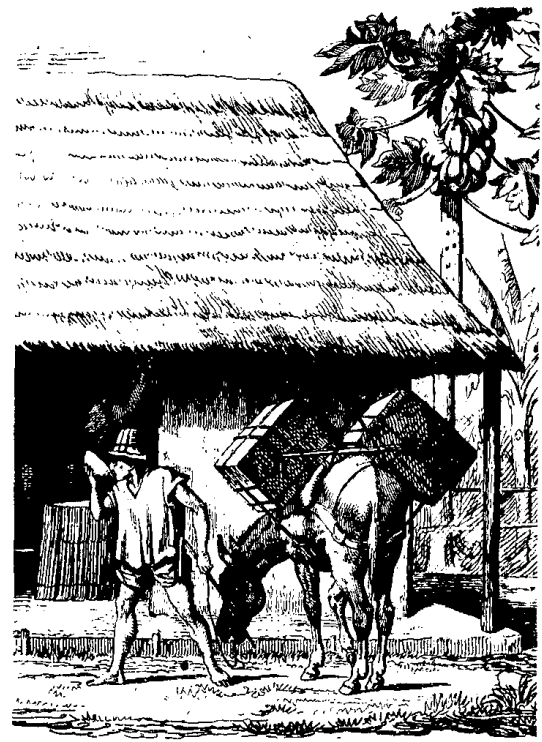

que se vio sometida esta institución en Cuba, derrotada por el ejército rebelde y desintegrada por el gobiemo revolucionario. ${ }^{23}$ Los militares dominicanos, al igual que el clero, entendieron de inmediato queuna "nueva Cuba" los haría

${ }^{23}$ A mediados de 1963, el entonces coronel Elías Wiessin y Wiessin, quien más tarde se destacaria en el golpe militar contra Bosch, publicó un artículo titulado "A todos mis hermanos de armas" en la Revista de las Fuerzas Amadas, año XIv, núm. 132, mayo-junio, 1963, donde planteó lo siguiente: "El comunismo, tiene un objetivo principal desde su formación y éste es destruir las fuerzas armadas, valiéndose de diferentes medios, como por ejemplo: 1) tratar de dividir los oficiales superiores de los subalternos; 2) crear animosidad de los alistados contra sus oficiales; 3) prometer a las fuerzas armadas bienestar después de su triunfo, etc. Estas mismas maniobras engañaron a la oficialidad y alistados del ejército cubano; ese mismo ejército actualmente no existe, gran parte de él fue asesinado, otros están en las cárceles y el resto en el exilio." Cfr. Libro Blanco de las Fuerzas Armadas..., p. 253. 
correr la misma suerte que los institutos castrenses cubanos. De ahí también el anticomunismo de los militares dominicanos, que los impulsaría a incursionar en la política nacional, particularmente en los procesos electorales, para evitar que gobiernos "pro comunistas" llegaran al poder.

Ese anticomunismo primitivo sería alentado por la oligarquía dominicana y el gobierno norteamericano, y serviria como pretexto para acusar a los partidos y líderes políticos que no respondieran enteramente a sus intereses. En este contexto, que no dejará de influir en procesos electorales posteriores, se celebran las primeras elecciones libres en República Dominicana. Sin embargo, esta triple injerencia (imperialismo-fuerzas armadas-Iglesia) en la política electoral dominicana no siempre se ha desarrollado simultáneamente, al menos con la misma fuerza; además se ha producido en etapas diferentes del proceso electoral, fundamentalmente durante la campaña y el escrutinio.

\section{2: LAS PRIMERAS ELECCIONES LIBRES EN LAS ULTIMAS DÉCADAS}

Después de la muerte de Trujillo tanto el Partido Dominicano-un instrumento con el que el dictador pretendía legitimar su gobiemo tras la celebración de elecciones cada cuatro años- como otros partidos menores con los que se intentaba dar la apariencia de pluralidad política, desaparecieron muy rápidamente del escenario dominicano. A su vez, en pocos meses se formaron más de una veintena de partidos de diversas tendencias políticas, en su mayoría con el objetivo de participar en el proceso electoral que para ese entoncesse avecinaba. La mayoría de dichos partidos fueron organizados por políticos que regresaban del exilio; sólo una minoría de los partidos había sido organizada por opositores que salian de las cárceles del dictador. De estos partidos muy rápidamente se destacaron tres: el Partido Revolucionario Dominicano (PRD), bajo el liderazgo de Juan Bosch, que había sido fundado a finales de la década de los treinta, por exiliados antitrujillistas; la Unión Cívica Nacional (UCN) que había sido fundada en 1961 en Santo Domingo como entidad patriótica, bajo el liderazgo de Viriato Fiallo, un opositor al régimen dictatorial que había permanecido en el anonimato; $y$ el Movimiento 14 de Junio, de orientación nacionalista y más tarde castrista, que había surgido a raíz de la expedición armada de 1959 contra Trujillo. El 14 de Junio se encontraba bajo el liderazgo de Manolo Tavarez Justo, destacado luchador antitrujillista. De estas tres organizaciones, sólo el 14 de Junio, a pesar de su amplio respaldo nacional, optó por no participar en las elecciones, en el entendido de que de hacerlo serviría de juego a la oligarquía y al imperialismo norteamericano.

Mientras la UCN representaba los intereses de la oligarquía y contaba con una base de apoyo social en las capas medias de los sectores urbanos, el PRD, en cambio, representaba un proyecto burgués, y contaba con una amplia base de sustentación social en el campesinado así como en los sectores marginales urbanos. Aunque ninguno de los dos partidos cuestionaba el orden de dominación capitalista, el PRDse presentaba comoun partido progresista, dentro delas condiciones históricas dominicanas, dispuesto a realizar una "revolución democrática", a la vez que a defender la soberanía nacional. El PRD era, además, un partido apegado a las ideas más liberales de la época, tanto en lo concerniente a la educación, la organización familiar, como al libre juego 
delasideas políticas, económicas y sindicales. Por ello, la disputa surgida entre la UCN y el PRD no era más que el enfrentamiento entre el partido de la oligarquía (UCN) -aunque carente de liderazgo político y con serias dificultades para ampliar su base de apoyo social-, y el partido de la burguesía (PRD), que contaba con un líder carismático, como lo ha sido Bosch, y una amplia base de sustentación social, pero que paradójicamente representaba el proyecto deuna burguesía que, como clase social, era inexistente. De ahí la gran contradicción y las limitaciones para que el PRD hiciera realidad su proyecto político, pero su gran ventaja consistía en que dicho partido contaba con un amplio respaldo popular; por su parte, la gran limitación y desventaja para la UCN era que carecía de un gran apoyo social, y en términos electorales esto es lo que cuenta. Por tal razón durante la campaña electoral la oligarquía trató desesperadamente de modificar la correlación de fuerzas sociales, desfavorable a la UCN, promoviendo un acercamiento con sus aliados "naturales", como lo eran el gobierno norteamericano, las fuerzas armadas y la Iglesia católica.

El gobierno de Estados Unidos estaba seriamente involucrado en la política dominicana, sobre todo a raíz de su participación en el asesinato del dictador Rafael Leónidas Trujillo. ${ }^{24}$ Las estrechas vinculaciones de Washington con los altos dirigentes de la UCN y con el Consejo de Estado que gobernaba el país no constituíanun secreto para nadie. Sin embargo, en las memorias del ex embajador norteamericano, John Bartlow Martin, ${ }^{25}$ se puede apreciar con posterioridad la gran diversidad de niveles de injerencia de la embajada norteamericana en la política

${ }^{24}$ Grimaldi, op. cit.

${ }^{25} \mathrm{John}$ Martin Bartlow, El destino dominicano, Ed. de Santo Domingo, Santo Domingo, 1975. electoral de la época. No obstante, durante la campaña electoral difícilmente Estados Unidos podía brindar más ayuda a la IUCN que la de su influencia, apoyo, y en todo caso con algúntipo de asesoría. Además, Washington sabía perfectamente, mediante sus servicios de inteligencia, que Bosch no era comunista, ni filocomunista. ${ }^{26}$ Bosch más bien era un defensor del sistema capitalista y amigo de los norteamericanos. El problema vendría más tarde, cuando Estados Unidos comprobara que Juan Bosch estaba interesado en introducir cambios sociales que podrían afectar los intereses estadunidenses en el país; que era un gobernante que defendía los intereses nacionales dominicanos y que no se le podía manejar a su antojo, como se acostumbraba a hacer con otros gobernantes de la región; que por considerarse un político demócrata, Bosch garantizaba en su gobierno plena libertad a los partidos políticos, incluyendo, claro está, a los de izquierda; y que dicho líder político no se prestaba a atacar la revolución cubana, como estaba interesado en hacer Estados Unidos. Cuando ello ocurrió, Washington no dudó en formar parte del frente oligárquico que conspiraría contra Bosch.

Las fuerzas armadas, por su parte, eran una institución que difícilmente podría ser arrastrada al frente oligárquico, porlo menos en el periodo de la campaña electoral. Losnexos de la alta oficialidad militar

\footnotetext{
${ }^{26}$ En un encuentro sostenido poco antes de las elecciones de 1962 entre monseñor Clarizio y el embajador norteamericano en República Dominicana, el embajador señalaba lo siguiente al religioso: "creía que debía saber que nosotros, el gobiernode Estados Unidos, había investigado la vida de Bosch durante 25 años por medio de nuestras agencias de espionaje y que, aunque todo era posible, que nosotros supiésemos, Juan Bosch no era comunista. Esto, opinaba yo, era algo que tanto él como otros religiosos tal vez debieran considerar", Martin, op. cit., p. 274.
} 
con la dictadura de Trujillo, pero sobre todo con sus crimenes, ${ }^{27}$ alejaba a los institutos castrenses de las posiciones de la UCN, partido que se caracterizaba por su fogoso discurso antitrujillista, típico de la oligarquía. En cambio, el discurso político del PRD con respecto al antitrujillismo era mesurado -aunque sí muy vehemente en contra de la oligarquía-, y si no inclinaba a los militares hacia el PRD, por lo menos dificultaba que pudieran ser atraídos por el frente oligárquico. Esta posición se modificaría al asumir el PRD el gobierno y oponerse a los privilegios demandados por la alta oficialidad, así como por la negativa de ésta a aceptar que los partidosy dirigentes de izquierda actuaran legalmente en el pais, como ocurre en cualquier gobierno demócrata.

En este contexto sólo la Iglesia católica hizo causa común con la oligarquía dominicana, con la que mantenía estrechos vínculos de clase e incluso políticos, al menos durante los dos últimos años de la

\footnotetext{
${ }^{27}$ A finales de la década de los cincuenta se creó en Santo Domingo el Servicio de Inteligencia Militar, uno de cuyos objetivos era "vincular y comprometer a la totalidad de las fuerzas armadas en hechos criminales a través de la represión política". La idea surgió a raíz del triunfo de la revolución cubana, pues se sostenía "que una de las razones principales por la que las fuerzas armadas de Cuba fueron derrotadas por la guerrilla y el movimiento de resistencia clandestino, residia en el hecho de que los militares cubanos no estaban todos comprometidos". En el argot dominicano, "comprometido" significa ser culpable "o estar enrolado, bien por comisión de crímenes o delitos o por el ejercicio de alguna iniquidad o por la observancia de un determinado tipo de conducta indigna desde todo punto de vista", Complot develado, Rafael Valera Benítez (pról.), Ed. Taller, Santo Domingo, 1984 , p. 22. Bosch por su parte señala sobre este mismo tema: "Todavía en sus últimos días, Trujillo acostumbraba preguntar de buenas a primeras a un oficial: '¿A cuántos ha matado usted?'. Esto lo hacía cuando invitaba a los oficiales a comer con él." Bosch, Crisis.... op. cit., p. 192.
}

tiranía. ${ }^{28} \mathrm{El}$ discurso anticomunista y las acusaciones que en el mismo sentido hacía la Iglesia católica contra Juan Bosch y el PRD sólo beneficiaba a la UCN, en tanto que intentaba restar apoyo electoral a aquél. Aunque la Iglesia oficialmente trató detomar distancia delas acusaciones contra Bosch con una carta pastoral de los obispos, ${ }^{29}$ lo cierto es que el clero, de manera individual, desde el púlpito y a través de los medios de comunicación no sólo acusaba a Bosch de comunista, sino que incluso advertía a sus feligreses "que serían excomulgados si votaban por el PRD" ${ }^{30} \mathrm{La}$ campaña anticomunista contra Bosch y el PRD llegó a tal grado que el partido tuvo que declarar que se retiraría de los comicios si la Iglesia no retiraba las acusaciones; Bosch, por su parte, se vio en la necesidad de retar, días antes de las eleccionesy antelos canales de televisión, a un sacerdote jesuita que lo acusaba de ser marxista-leninista. El debate constituyó el mejor cierre de campaña para Bosch, ya que el sacerdote español tuvo que retractarse delas acusaciones formuladas, con lo que el programa se convirtió en el de mayor teleaudiencia nacional. La suerte estaba echada a partir de ese momento. La UCN tendría que recurrir a otros medios si quería tomar el poder,

${ }^{28}$ A finales de enero de 1960, el obispado dominicano hizo pública la "Carta pastoral", que se leyó en todas las iglesias, donde tomaba posición respecto a la dictadura y por la represión que se había desatado a raíz de una conspiración descubierta para asesinar a Trujillo. Varios seminaristas habian sido detenidos y acusados de estar implicados en dicha conspiración. A partir de esa fecha se puede considerar que se produce una ruptura entre la Iglesia católica y la dictadura de Trujillo. William Wipfler, Poder, influencia e impotencia. La Iglesia como factor sociopolítico en República Dominicana, CEPAE, Santo Domingo, 1980, pp. 108-147.

29 Ibid., p. 181.

${ }^{30} \mathrm{Ibid}$., p. 176. 
pues con la campaña electoral no lograba incidir en el sector social que apoyaba al PRD. Y en efecto, el 20 de diciembre, dia delas elecciones, el PRD obtuvo una aplastante victoria, con 619491 votos $(58.7 \%)$, contra 317327 votos (30.0\%) de la UCN. La representación parlamentaria alcanzada por el PRD también guardaba las mismas proporciones: 22 senadores y 49 diputados para el PRD, y tan sólo cuatro senadores y 20 diputados para la UCN. Ello significaba que el PRD tenía las manos libres para realizar todas las reformas económicas, sociales, políticas, juridicas e institucionales que parlamentariamente fueran necesarias. La primera y más importante de estas medidas sería la nueva Constitución.

Mientras el gobierno tomaba sus primeras medidas, la campaña anticomunista contra Bosch se incrementaba en vez de disminuir. Tan pronto fue aprobada la Constitución, a finales de abril de 1963, ésta se convirtió en el blanco preferido de los ataques de la oligarquía. Según la Iglesia y la UCN, la Constitución era la mayor prueba del comunismo del gobierno de Bosch. De ahí que la oligarquía formara el Comité de Reafirmación Cristiana, con el fin de realizar concentraciones de "afirmación cristiana" que se proponían "detener el comunismo" que se había infiltrado en el gobierno, según señalaban sus organizadores. ${ }^{31}$

31 Durante el gobierno de Bosch, en la prensa dominicana se publicaban reportajes y documentos con encabezados como los siguientes: "Pueblo reafirma fe en cristianismo y jura luchar para salvar el país del comunismo"; "En defensa de la patria. Comunicado (...) Nosotros, los abajo firmantes, confiamos en que nuestras fuerzas armadas se mantendrán alertas y vigilantes para defensa de nuestros intereses nacionales, contra los ataques de las fuerzas comunistas, que son las encarnizadas enemigas de la democracia y de la
La gran diferencia existente entre la campaña anticomunista desarrollada contra Bosch, antes y después de las elecciones, es que antes de los comicios sólo la Iglesia católica se unió a la oligarquía, por lo menos de una manera abierta y decidida; en cambio, después que Bosch asumió el poder y comenzó a tomar las primeras medidas de su gobierno, la oligarquía consiguió arrastrar a su posición al gobierno norteamericano y a las fuerzas armadas, con lo cual se modificó sustancialmentela correlación de fuerzas políticas contra el gobierno de Bosch. Una vez que la oligarquía consiguió ampliar su frente, mediante la triple alianza formada por el imperialismo-fuerzas armadas-Iglesia católica, el gobierno elegido libremente por el pueblo en las últimas cuatro décadas fue derrocado por un golpe de Estado en septiembre de 1963. Con tal medida entraba en crisis la credibilidad del sistema político-electoral en la República Dominicana. Este hecho traería serias consecuencias en la vida política y social del país, pues al cerrarse los canales institucionales los dirigentes y las organizaciones políticas recurririan a métodos violentos con el fin de instaurar un sistema democrático.

\section{6: ELECCIONES EN UN PAIS OCUPADO MILITARMENTE}

En 1963, a raíz del golpe de Estado, la oligarquía domincana asumió nuevamente el poder político de la nación. A pesar de sus promesas de elecciones, con

\footnotetext{
libertad, en América y el mundo"; "Multitud en La Vega reafirma repudio a doctrina comunista"; "Comunismo amenaza país, afirma coronel Medrano en acto centenario restauración", Cfr. Libro Blanco de las Fuerzas Armadas..., Ed. El Caribe, Santo Domingo, República Dominicana.
} 
las que intentaba aplacar el descontento popular a la vez quelegitimarse, no pudo mantenerse en el poder más de año y medio. En abril de 1965 un grupo de militares apegados a la constitucionalidad, dio un golpe de Estado con el objetivo de reponer a Bosch en la presidencia. El golpe de Estado fracasó a causa de la oposición que encontró en el sector militar que más se había identificado con la oligarquía y que se había comprometido con el golpe de Estado de 1963. El conflicto desembocó en una guerra civil, donde los constitucionalistas, apoyados por el pueblo en armas, después de sólo tres días de lucha, se aprestaba a derrotar a las fuerzas militares prooligárquicas. Justamente en ese momento, el 28 de abril, intervienen las tropas norteamericanas para apoyar a los militares antiboschistas. En la nueva coyuntura que se presentaba, la triple alianza (imperialismo-fuerzas armadas-Iglesia católica) quedó resquebrajada: las fuerzas armadas se encontraban profundamente divididas, con dos bandos en pugna irreconciliables, por un la do los constitucionalistas, lidereados por el coronel Francisco Caamaño Deñóy, por otrolado, ios antiboschistas encabezados por el general Elías Wessin y Wessin; la Iglesia católica, que en un principio apoyó a las tropas de ocupación, muy rápidamente se dividió en dos bandos, uno conservador que se alineó junto las fuerzas. de ocupación, y otro progresista que se identificó y actuó al la do de los sectores constitucionalistas. Sólo las fuerzas norteamericanas actuaban con total unidad. De ahí que le tocara a estas últimas recomponer y hegemonizar el resquebrajado frente oligárquico dominicano.

Después de más de cuatro meses de resistencia armada, las tropas norteamericanas, no obstante su poderío bélico, fueron incapaces de derrotar al movi- miento constitucionalista, por lo que hubo que buscar una salida negociada al conflicto. De la negociación resultó Héctor García Godoy como presidente provisional; se encargaría de convocar a elecciones, y de esa manera tratar de recuperar la institucionalidad del país. Sin embargo, el proceso no fue tan sencillo como pudiera parecer. En primer lugar, el país se encontraba ocupado militarmente por tropas extranjeras que habían llegado en defensa de uno de los dos bandos en pugna; en segundo lugar, la intervención militar se había producido para evitar que Juan Bosch y el PRD retomaran el poder, lo cual los ponía en desventaja frente a su opositor joaquín Balaguer, si las elecciones se celebraban con el país ocupado por Estados Unidos; en tercer lugar, uno de los pretextos de la intervención fue que el movimiento constitucionalista estaba controlado por comunistas, lo cual descalificaba a todas las organizaciones y dirigentes de izquierda, a la luz de los intereses norteamericanos.

No obstante la complejidad de la coyuntura señalada, muy rápidamente se destacaron dos fuerzas políticas y sociales para participar en las anunciadas elecciones: la representada por el PRD con Juan Bosch como candidato a la presidencia y la del Partido Reformista con Joaquín Balaguer como candidato. Si exceptuamos a la UCN, que participaba con Rafael Bonelly como candidato, los demás partidos conservadores que existían antes de la ocupación cerraron filas con el Partido Reformista o desaparecieron del escenario político dominicano. En realidad el PR pasó a convertirse en el verdadero heredero del nuevo orden político, económico, social y militar que impusieron las tropas de ocupación.

De todas maneras, el gobierno provisional de Héctor García Godoy trabajó 
activamente en la reestructuración del sistema electoral que normaría los comicios que se avecinaban. De un total de 304 leyes emitidas por García Godoy, de septiembre de 1965 a junio de 1966, fecha en que se celebraron las elecciones, 21 leyes fueron para regular y organizar los sufragios generales. Algunas de la leyes o disposiciones tenían el claro propósito de favorecer al candidato predilecto de Washington, Joaquín Balaguer. Entre estas disposiciones se encontraban las siguientes: supresión de la cédula electoral; permiso para votar en cualquier mesa electoral; permiso para que las mujeres mayores de 25 años de edad pudieran votar sin identificación alguna. Esta última disposición fue acordada a solicitud del propio Partido Reformista, bajo amenaza de retirarse de las elecciones.

Con estas medidas las fuerzas intervencionistas quisieron asegurarse los mecanismos que le permitieran el fraude con una relativa facilidad, pero además inclinaban la balanza a favor de Balaguer en tanto que se privilegiaba a toda la población femenina de más de 25 años de edad para emitir su voto. Esta población era, sin lugar a duda, la más conservadora del electorado dominicano y constituía la mayor base de apoyo social del Partido Reformista de Balaguer, como se comprobaría posteriormente.

Mientras se tomaban estas disposiciones para favorecer a Balaguer, se perseguía a los dirigentes de izquierda y a todos los sectores progresistas que habían mostrado una posición nacionalista. A Juan Bosch, por ejemplo, no se le permitió salir de su casa a realizar su campaña electoral, bajo amenaza de muerte de los altos mandos militares. A principios de marzo, es decir, tres meses antes de las elecciones, un avión AT-6, de la fuerza aérea dominicana realizaba vuelos rasantes, picadas y otras maniobras sobre la residencia de Bosch. El hostigamiento contra las fuerzas progresistas alcanzó una enorme dimensión, mientras Balaguer y su partido recibían todo el apoyo para realizar su campaña electoral.

En este contexto de desigualdad, donde, si bien la Iglesia católica había manifestado su disposición de mantener neutralidad política, las fuerzas armadas y las tropas de ocupación apoyaban abiertamente a uno delos candidatos presidenciales, no es de extrañarse que los resultados electorales le dieran la victoria a Joaquín Balaguer. En las elecciones de junio de 1966, el PR de Balaguer obtuvo 759887 votos $(56.7 \%)$, frente a 494570 votos $(36.7 \%$ ) del PRD. A su vez, la representación en el Congreso Nacional fue la siguiente: $\mathrm{PR}$, con 22 senadores 48 diputados; PRD, cinco senadores y 26 diputados. En realidad las elecciones sólo sirvieron como instrumento para legitimar en el poder a Joaquín Balaguer.

Una vez en el poder, Balaguer dio inicio a un intensa persecución contra los constitucionalistas, a quienes llevó a las cárceles, envió al exilio o simplemente los asesinó. Simultáneamente emprendió un proyecto reformista con el que intentaba neutralizar y más tarde ganarse una amplia base de apoyo social. En enero de 1966, aún con las tropas estadunidenses ocupando el país, durante la campaña electoral, Joaquín Balaguer pronunció un discurso donde definía con claridad el proyecto reformista que se proponía ejecutar, una vez ganara los comicios electorales del mismo año. Balaguer señalaba:

Nadie duda ya, sobre todo después del estallido revolucionario del $24 \mathrm{de}$ abril, que aquíno puede haber orden estable si no se emprende con seriedad un movimiento de 

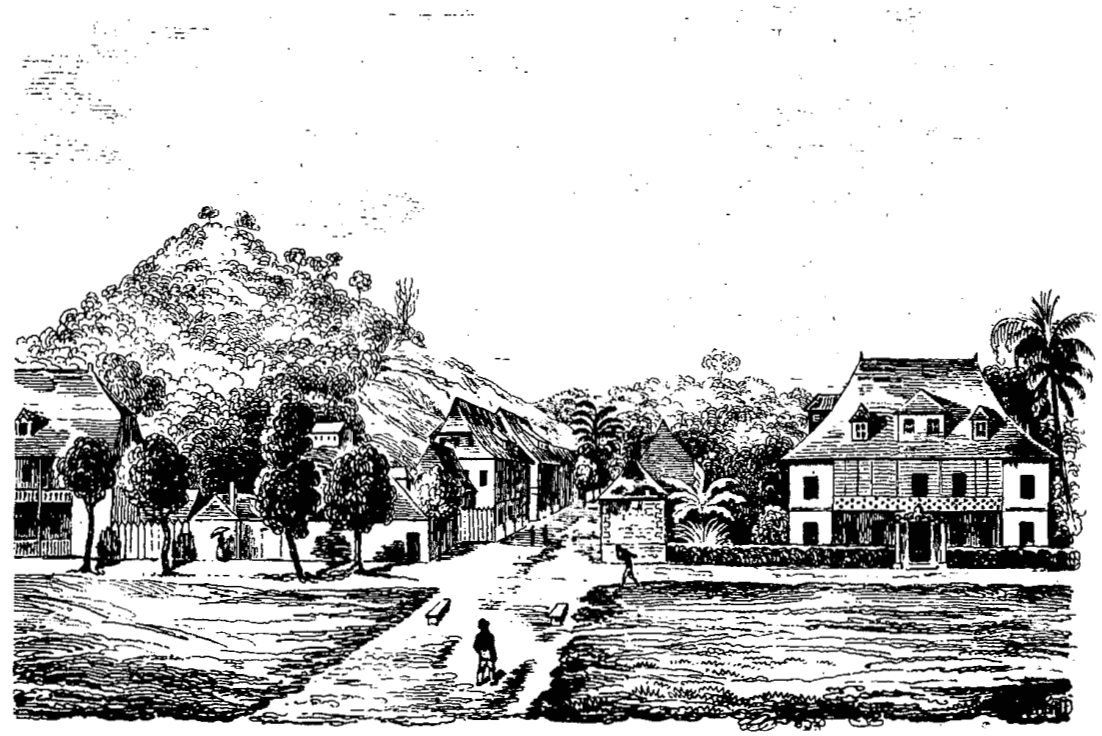

reformas que tienda a elevar los niveles de vida de nuestros núcleos sociales mayoritarios [...] creemos que esa labor puede llevarse a cabo mediante una revolución pacífica que opere las transformaciones que sean necesarias sin atentar contra las bases en que nuestra sociedad tradicional ha sido organizada. ${ }^{32}$

Sin embargo, la elección de Joaquín Balaguer como presidente de la república y la evacuación de las tropas norteamericanas no implicaban la recuperación de la soberanía nacional. Después de la desocupación se duplicaron los miembros del Grupo Asesor de Asistencia Militar (MAAG) del gobierno de Estados Unidos, lo que hacía pensar que el control de las fuerzas armadas dominicanas quedaba a cargo de estos asesores; pero además, la mayoría de las instituciones

${ }^{32}$ Joaquín Balaguer, La marcha bacia el Capitolio, Santo Domingo, 1973, p. 78. nacionales más importantes comenzaron a ser penetradas por "misiones" de ayuda o cooperación de Estados Unidos o de organismos internacionales, como la Agencia Internacional para el Desarrollo (AID) y el Banco Interamericano para el Desarrollo (BID), controlados por Washington. Las tropas de ocupación, antes de su evacuación, crearon la plataforma política, económica y militar que permitiría a Estados Unidos mantener el control del país como una especie de protectorado. Balaguer era el personaje clave para tales fines.

\section{Y 1974: ELECCIONES SIN COMPETITIVIDAD Y CREDIBILIDAD}

En su intento por permanecer y legitimarse en el poder, el presidente Joaquín Balaguer celebró dos de los procesos electorales de más baja credibilidad que 
se hayan realizado en el país en los últimosaños. Sin un respaldo popular quele garantizara retener el poder mediante comicios libres, Balaguer se apoyó en las fuerzas armadas, institución que pasó a jugar el papel de partido político al defender pública $y$ abiertamente la candidatura balaguerista. El alto mando oficial realizaba pronunciamientos proselitistas en favor de Balaguer y en los propios cuarteles militares se colocaba propaganda del PR; los militares que patrullaban las ciudades lo hacían portando en el cuello el emblema del Partido Reformista a manera de pañuelo y el distintivo balaguerista en el fusil.

Simultáneamente a esta injerencia militar en la política electoral, en el país actuaba una fuerza parapolicial denominada Frente Democrático Antiterrorista y Anticomunista, que el pueblo bautizó con el nombre de La Banda, pues en realidad no era más que una banda de malhechores a sueldo. La misión de La Banda era realizar el trabajo sucio, pues de hacerlo los cuerpos policiales y militares levantarían serias protestas en la población. ${ }^{33} \mathrm{La}$ impunidad de La Banda quedó de manifiesto cuando el propio presidente Joaquín Balaguer declaró públicamente que se trataba de acciones de "fuerzas incontrolables", frente a las que el poder del gobiemo se sentía incapacitado para impedir sus actos.

No obstante el clima de terror impuesto, el gobierno convocó a elecciones para mayo de 1970. A estos comicios no se presentó el PRD, cuyo líder, Juan Bosch, había llegado al más alto nivel de crítica de la denominada democracia representativa. En ausencia del PRDy de todo partido que representara una verdadera opción opositora, se presentaron pe-

${ }^{3.3}$ En sólo seis meses, de abril a octubre de 1971, La Banda realizó 265 actos criminales. queñas agrupaciones políticas sin peso significativo en la sociedad, en su mayoría desprendidas del mismo Partido Reformista, o pertenecientes a las fuerzas oligárquicas. Los resultados electorales no sehicieron esperar: 653565 votos (52.8\%) para el PR, contra 252760 votos (20.4\%) para el Movimiento de Integración Democrática (MIDA), una escisión del Partido Reformista, que no tenía fuerza alguna para presentarse como opción. El resto de la votación se distribuyó entre cuatro agrupaciones políticas más, dentro de las que se destacaba el Partido Quisqueyano Demócrata, bajo el liderazgo del general retirado Elías Wessin y Wessin, quien se había destacado en el golpe de Estado que derrocó a Bosch en 1963 y después al lado de las fuerzas de ocupación norteamericanas, en 1965. Años más tarde, durante la administración balaguerista de 1986-90, Wessin y Wessin sería reintegrado a los institutos castrenses para ser nombrado secretario de las fuerzas armadas por el presidente Joaquín Balaguer.

Reelegido en la presidencia en 1970, Balaguer intenta desarrollar lo más profundamente posible su programa de reformas sociales, única vía para lograr concitar un verdadero apoyo popular que le permitiera legitimarse en el poder mediante elecciones competitivas. Deahí todo el esfuerzo puesto en la reforma agraria alrededor de los añossetenta, para lo cual hizo dictar las leyes agrarias de 1972 con el fin de impulsar su proyecto agrario y consolidar así su influencia en el campesinado. Este proyecto, sin embargo, implicaba un serio riesgo político para Balaguer pues lo llevaría a enfrentarse al sector terrateniente de la oligarquía dominicana, que hasta ese momento le había brindado total apoyo. No es por casualidad que las leyes agrarias fueron aprobadas en 1972, cuando ya la etapa 
regresiva había cumplido la importante tarea de eliminar físicamente a los líderes de izquierda y de desarticular sus principales organizaciones. Con el objetivo de modificar la correlación de fuerzas políticas y sociales, pero que el enfrentamiento con la oligarquía terrateniente fuera menos riesgoso, Balaguer pidió a las cámaras legislativas el reconocimiento del Partido Comunista Dominicano (PCD), organización que apoyaba el proyecto agrario, con el propósito de agudizar las contradicciones entre la oligarquía terrateniente y el sector reformista representado por Balaguer. Con dicha medida Balaguer perseguía dos objetivos: por un lado, hacerse de un aliado para enfrentar a la oligarquía terrateniente; por otro, dividir aún más a la izquierda. De 1972 a 1975 la reforma agraria logróbeneficiara 122326 personas con la repartición de 97056 hectáreas en las que se asentaron 18657 parceleros.

Sin duda el proyecto de reforma agraria le permitió a Balaguer ampliar su base de apoyo social entre el campesinado, pero a su vez le generó contradicciones con la oligarquía terrateniente, y muy particularmente conla ganadera. Esas contradicciones abrieron una fisura en el gobierno reformista que el PRD supo aprovechar muy bien con fines electorales para los comicios de 1978.

Pero antes de llegar a ellos pasemos a la jornada electoral de 1974, la cual se celebra en un momento de serias contradicciones para el reformismo. Estas contradicciones del reformismo de Balaguer quisieron ser aprovechadas por la oposición, mediante un amplio frente político denominado Bloque de la Dignidad Nacional, integrado por quince partidos opositores, de la derecha, del centro y de la izquierda, pero bajo el liderazgo de Juan Bosch en el PRD. Sin embargo, este frente fracasó muy rápida- mente, sobre todo a raíz de la renuncia de Bosch del PRD, a finales de 1973. Mientras tanto algunas de las organizaciones que habían integrado el Bloque de la Dignidad Nacional trataron de formar otro frente, denominadoAcuerdo deSantiago, el cual tampoco tuvo grandes posibilidades de consolidarse. No obstante los fracasos de la oposición por articular un frente electoral, el aislamiento político que se perfilaba sobre Balaguer tendía a crecer pues las mismas fuerzas sociales y políticas que lo habían apoyado le retiraron su colaboración. Por eso Balaguer recurrió a los institutos castrenses en busca de apoyo ya que allí contaba con un alto mando militar que secundaba su reelección. En tales condiciones, pero sobre todo por la incapacidad de articular un frente opositor amplio, las diferentes organizaciones políticas opuestas a Balaguer decidieron abstenerse de participar en las elecciones. Ante esta situación, Balaguer logró que un pequeño partido, el Partido Demócrata Popular, bajo la dirección del contralmirante retirado Homero Lajara Burgos, aceptara participar como opositor, con lo que daba la apariencia de pluralidad y competitividad políticas. En tal coyuntura elíndice de abstencionismo se elevó considerablemente (25.1\%), aunque en realidad no revelaba la verdadera posición de la población empadronada, pues en República Dominicana las elecciones son obligatorias. Por ello al índice de abstencionismo habría que sumarle el de votos nu$\operatorname{los}(23.95 \%)$, lo cual representaría $45.05 \%$ de losinscritos en el Registro Electoral, es decir, 912904 votantes ${ }^{34}$ Sin embargo, ello no impidió que Balaguer proclama-

${ }^{34}$ Elsa Expósito, "Balaguer gana otra vez en el 70; Lora y Wessin fueron entonces los principales rivales del PR", El Siglo, 27 de enero de 1990, Santo Domingo, p. 12. 
ra su triunfo electoral como el mayor logrado por candida to alguno en la historia política del país. Los cómputos a los que Balaguer hacía referencia eran los siguientes: 942726 votos (84.7\%) para el Partido Reformista y el balaguerista Movimiento Nacional de la Juventud, que había participado en coalición con el primero; al Partido Demócrata Popular, de Lajara Burgos, que fungía como opositor, se le atribuyeron 170693 votos (15.3 por ciento).

Como se observará, tanto en las elecciones de 1970 como en las de 1974, la polarización bipartidista desaparecióa causa de la falta de competitividad para reaparecer en las elecciones de 1978 , cuando nuevamente el PRD volvería a participar en la contienda electoral.

\section{8: NUEVA BUSQUEDA DE LA DEMOCRACIA SOCIAL}

A mediados de la década de los setenta el modelo de dominación balaguerista había entrado en crisis. De 1975 a 1976 el valor de las ventas de azúcar decayó de 592 millones de dólares a 299 millones -no obstante haber aumentado la producción-, pues el precio de la libra pasó de 65 centavos en 1974 a diez en 1976. En contrapartida, en 1977 el paîs duplicó las importaciones de productos alimenticios, con relación a las de los cuatro años anteriores, y cuadruplicó la suma destinada a las importaciones de petróleo y sus derivados. A su vez, la tasa de crecimiento del PBI, que en 1967-73 era de $11 \%$, en 1977 pasó a ser de 3.3 por ciento.

Por otro lado, las condicionessociales y políticas que habían permitido al Partido Reformista asumir el poder en 1966 sehabían modificado considerablemente. La Iglesia católica, aliada "natural" de Balaguer, comenzó a formular serias críti-

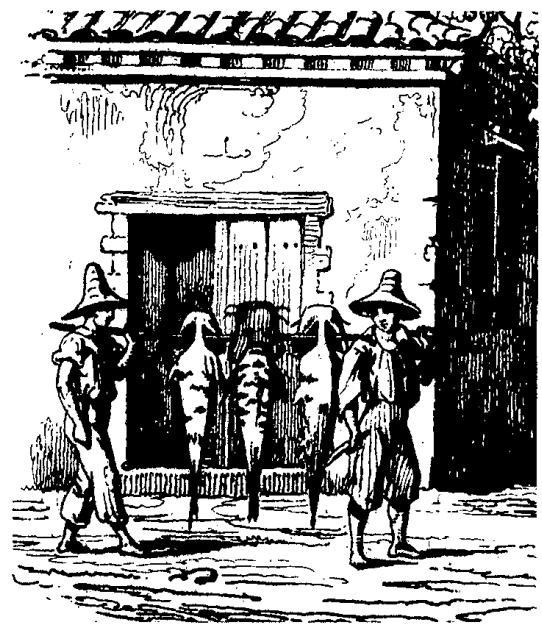

cas a la corrupción administrativa del gobierno; Washington, por su parte, parecía mostraruna posición de neutralidad ante la eventual victoria del opositor PRD. Sólo los institutos castrenses, que el primer mandatario manejaba maquiavélicamente en función de sus intereses, seguían brindandototal apoyo a la política reeleccionista del gobierno. En sintesis, la triple alianza (imperialismo-fuerzas armadas-Iglesia católica), que tan decidido apoyole había brindado a Balaguer durantela segunda mitad de la década de los sesenta y la primera de los setenta, se había debilitado considerablemente, por lo menos en lo que se refiere a cerrar filas en torno al caudillo conservador. Dentro del mismo PR las pugnas de facciones se habían incrementado; la aplicación de la reforma agraria había contribuido a ello y por lo menos un sector de la oligarquía, precisamente el de más fuertes intereses en el agro, optó por separarse del PR y lanzarse a la búsqueda del poder con su propio partido, el Movimiento de Salvación Nacional, dirigido por el terrateniente Luis Julián Pérez. 
No obstante el deterioro señalado, Balaguer había logrado ampliar considerablemente su base de apoyo social, sobre todo en el campo, a partir de la reforma agraria. En los medios urbanos, particularmente en las barriadas de capas medias y bajas, Balaguer había empezado a disputar un área social que tradicionalmente había controlado el PRD. Para incidir en los medios urbanos Balaguer se valió de su política de construcción de viviendas y de su asistencialismo social.

El PRD, en cambio, estaba realizando un acercamiento a los sectores de la burguesía y oligarquía descontentos con Balaguer, lo cual tenía mucha importancia en términos de política electoral.

En síntesis, el desgaste del modelo de dominación balaguerista, la crisis interna del partido de gobierno, el auge del PRD y las presiones internas y externas se conjugaron para que Balaguer accediera a garantizar unas mínimas condiciones de seguridad para los partidos de oposición durante la campaña electoral. Esta coyuntura permite que el PRD y otros partidos diversos de oposición participen en las elecciones. Sin embargo, a la luz de la interpretación de ciertos sectores del balaguerismo, particularmente de los militares que se encargaban de dirigir la campaña electoral del PR, la victoria de Balaguer era un hecho. De ahí que cuando los escrutinios comenzaron a arrojar un resultado desfavorable al $\mathrm{PR}$, los militares irrumpieran en la Junta Central Electoral con el fin de interrumpir el conteo de los votos y dar un golpe de Estado que les permitiera retener el poder. Sin embargo, esto último no fue posible, en parte por las pugnas surgidas entre los miembros de la alta oficialidad, y en parte por las presiones externas, particularmente del gobierno norteamericano, que tomó cartas en el conflicto. El resultado fue una componenda entre el PRD, el PR y el gobierno norteamericano, que se denominó "fallo histórico" y en el que al PRD se le reconocía el triunfo electoral, a cambio de que aceptara la alteración de los cómputos en cuatro provincias del país, con lo cual el PR lograba mayoría en el Senado. De esa manera, el PRD àsumía el poder a medias pues la Cámara de Senadores pasaba a ser controlada por la oposición balaguerista.

Los resultados oficiales de las elecciones fueron los siguientes: 856084 votos (51.7\%) para el PRD y 698273 votos (42.2\%) para el PR. Por su parte, el Congreso Nacional quedó configurado así: 16 senadores (59.3\%) y 43 diputados (47.3\%) para el PR, en tanto que el PRD obtuvo once senadores (40.7\%) y 48 diputados ( $52.7 \%$ por ciento).

\section{Y 1986: RESQUEBRAJAMIENTO DE LA POLARIZACIÓN BIPARTIDISTA}

Existen algunos factores que consideramos fundamentales para explicar el perfil del resquebrajamiento de la polarización bipartidista que ha caracterizado los procesos electorales en República Dominicana en las últimas décadas. El más importante de ellos, a nuestro parecer, es el desgaste que han sufrido los modelos de dominación aplicados por el Partido Reformista y el Partido Revolucionario Dominicano, en sus respectivos periodos administrativos; el PR, de 1966 a 1978 y de 1986 a 1990, y el PRD, de 1978 a 1986. Ninguno de los dos partidos ha logrado sentar las bases que permitan al pais lograr un desarrollo sostenido. Al contrario, de 1966 a 1990 la deuda externa se incrementó sustancialmente. Hasta 1966 República Dominicana había contraído una deuda externa de 158.1 millones de dólares, en cambio en 1977 
dicha deuda pasó a ser de 1076.8 millones. En 1990 la deuda externa es de alrededor de los 4000 millones de dólares. Paralelamente a este endeudamiento, la moneda se ha devaluado en más de un mil por ciento; la tasa de desempleo y subempleo ha alcanzado índices insospechables; y el déficit alimentario ha aumentado, produciéndose un fuerte deterioro social, que abarca todas las instancias sociales.

Ante esta situación, diversos sectores nacionales han manifestadosu interés por buscar una nueva opción política que permita realizar los cambios económicos y sociales que posibiliten superar la crisis y la dependencia económica que vive el pais.

Un segundo factor que ha hecho posible el mencionado resquebrajamiento de la polarización bipartidista es el debilitamiento de la triple alianza (imperialismo-fuerzas armadas-Iglesia católica), particularmente a raíz del proceso de profesionalización de las fuerzas armadas llevado adelante por el gobierno del PRD, en particular durante la administración de Salvador Jorge Blanco. ${ }^{35}$ Esta profesionalización, aunque no corresponde a los niveles que la propaganda oficialista le ha atribuido, por lo menos ha permitido la eliminación del crimen planificado y de la forma abierta que tenían los militares de intervenir en la vida partidaria, sobre todo en el proceso electoral, en defensa del partido de gobierno; y más bien, muchos de los militares que participaron activamente desde los institutos castrenses apoyando a Balaguer, han pasado a organizar su propio partido político en calidad de militares retirados, es decir, como veteranos. Nos referimos al denominado Partido Nacional de Ve-

\footnotetext{
${ }^{35}$ Mariñez, "Las fuerzas armadas...", op. cit.
}

teranos Civiles, organización de singular interés para los politólogos dominicanos e incluso latinoamericanos.

En tercer lugar, como producto del ascenso al poder del PRD en 1978, se inició una mayor apertura política para que lasorganizaciones democráticas puedan articulary presentarun proyecto nacional que tenga acogida en amplios sectores de la población. Entendemos que la izquierda tradicional no ha sabido aprovechar esta oportunidad política por diversas razones que no viene al caso analizar en este momento, pero dentro de las que se destacan la atomización de la misma izquierda y su discurso político, que no ha logrado interesar a las grandes mayorías nacionales. Quizá el más serio intento por superar esta atomización se produjo durante las elecciones de 1982, cuando se logró formar dos grandes bloques: la Unidad Socialista (integrada por el Partido Comunista y el Movimiento por el Socialismo) e Izquierda Unida (formada por el Bloque Socialista y Unidad Patriótica Antiimperialista). Sin embargo, dicha unidad sólo tuvo fines electorales, por lo que ambos bloques de unidad desaparecieron muy rápidamente; en ello quizás influyó la poca repercusión que se consiguió durante el proceso electoral. Sumados los dos bloques, apenas llegaron a obtener 34731 votos (1.8 por ciento).

Una situación muy diferente se presenta en el PLD, partido que ha logrado articular un discurso político con el cual las grandes mayorías nacionales han sido llamadas. El PID, además, bajo el liderazgo de Juan Bosch y con su estructura y organización de partido militante, no ha sufrido la atomización que caracteriza a la izquierda tradicional. Si analizamos la participación electoral del PLD desde 1978, cuandose presentó por primera vez a los comicios generales, encontramos el 


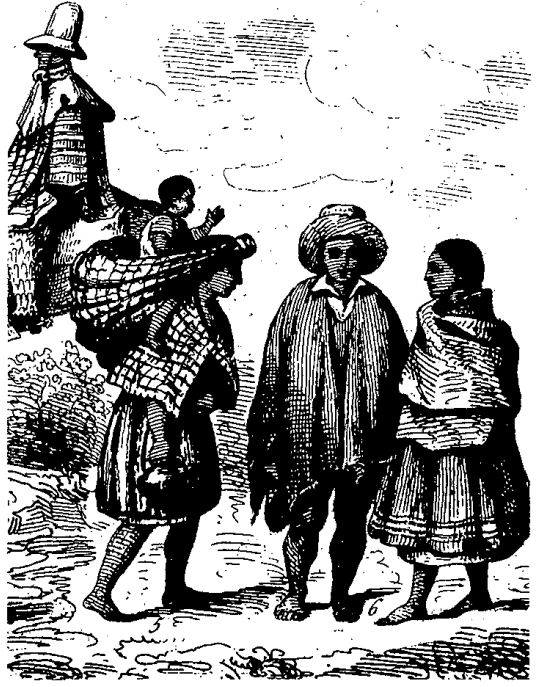

siguiente perfil de avance, que no es más que la expresión del apoyo popular que ha ido ganando y que a su vez marca el punto de partida del resquebrajamiento de la referida polarización bipartidista.

Veamos en primer lugar los resultados generales de las elecciones de 1982 y 1986. En las de 1982 la votación se distribuyó de la siguiente manera: 854868 votos (46.7\%) para el PRDy 717719 votos (39.9\%) para el PR. En las elecciones de 1986 el resultado fue el siguiente: 855565 votos (40.5\%) para el PR y 706588 votos (33.5\%) para el PRD. En cambio, si observamos los resultados electorales para el PLD, se encontrará que su crecimiento se ha ido produciendo a costa de la reducción del apoyo electoral de los dos partidos antes mencionados. En 1978 el PLD obtuvo 18375 votos (1.1\%); era la primera vez que se presentaba a unos comicios generales. En 1982, en cambio, tuvo un aumento considerable al alcanzar 179849 $\operatorname{votos}(9.8 \%)$, lo que le permitió, además, colocar siete diputados en el Congreso; en las elecciones de 1986, que hasta el momento son las últimas que se han celebrado en el país, el PLD obtuvo 387881 votos $(18.4 \%)$ duplicando así su votación para colocar dos senadores y 16 diputados en el Congreso.

Este crecimiento sostenido en el plano electoral carece de precedente en la historia política dominicana, por lo menos de las últimas décadas. Los partidos conservadores, que son los únicos que han logrado obtener porcentajes significativos en los procesos electorales después de 1962 -si exceptuamos a los que han polarizado las eleciciones- han surgido de manera coyuntural, por lo que han desaparecido con mucha rapidez.

El último factor que debe ponerse a consideración es que ante el desgaste sufrido en el poder por el Partido Reformista y el Partido Revolucionario Dominicano, el PLD, bajo el liderazgo de Juan Bosch, se ha convertido en una opción de poder; esto se debe no sólo al proyecto nacional que dicho partido ha planteado, sino también porque la única referencia de las últimas décadas en la memoria histórica del pueblo dominicano de un gobierno que hubiese intentado desarrollar un proceso democrático tanto en lo económico como en losocial de manera prioritaria, es el de Juan Bosch en 1963, que fue derrocado a los siete meses.

Por ello, si el PLD mantiene la mism 1 tendencia de crecimiento electoral sostenido en los últimos años, en 1990 la polarización bipartidista habrá quedado totalmente resquebrajada o, en su defecto, el PLD se convertirá en uno de los dos extremos de la nueva polarización electoral que pueda surgir. Consideramos que esta tendencia es válida siempre y cuando el proceso electoral no sea alterado por el fraude, práctica nunca descartable, sobre todo cuando el partido del gobierno participa en las elecciones. 
PRD

Cuadro 1

REPRESENTACION EN EL CONGRESO

Partido

Revolucionario

Dominicano

$\begin{array}{llll}22 & 49 & 05 & 26\end{array}$

$\begin{array}{llllll}11 & 48 & 17 & 62 & 07 & 48\end{array}$

UCN

Unión Civica

Nacional

$04 \quad 20$

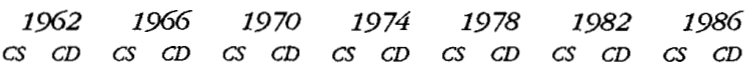

PNRD

Partido

Nacionalista

Revolucionario

Democrático $\quad 01 \quad 04$

PRSC

Partido

Revolucionario

Social Cristiano

PR

Partido

Reformista

MIDA

$\begin{array}{llllllllllll}22 & 48 & 21 & 45 & 27 & 86 & 11 & 43 & 10 & 50 & 21 & 56\end{array}$

Movimiento de

Integración

Nacional

MNJ

Movimiento

Nacional de

la Juventud

PQR

Partido

Quisqueyano

Demócrata

PDP

Partido

Demócrata

Popular

$00 \quad 03$

MVP

Movimiento

Voluntad

Popular

$01 \quad 15$

MMP

Movimiento

Municipal

del Pueblo

$00 \quad 01$

$00 \quad 01$ 


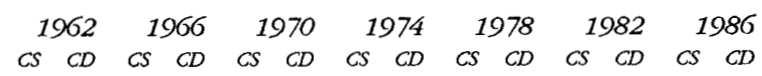

PLD

Partido de la

Liberación

Dominicana

$00 \quad 07 \quad 02 \quad 16$

PAC

Partido de

Acción

Constitucional

$00 \quad 01$
cs: Cámara de Senadores
CD: Cámara de Diputados

Fuentes: Elaborado con base en Julio Campillo Pérez, Elecciones dominicanas, Academia Dominicana de Historia, Santo Domingo, vol. XLIX; Dario Contreras s.f., Elecciones Dominicanas, 1962-1982: datos y análisis. Comportamiento electoral dominicano, Ed. Corripio, Santo Domingo. También se han utilizado otros textos citados en la bibliografía.

\section{Cuadro 2 \\ POLARIZACION ELECTORAL}

$A \tilde{n} o$

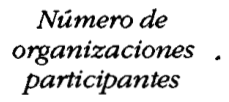

1962

1966

1970

1974

1978

1982

1986
Año Votosobtenidos por el partido ganador

08
10
06
02
12
14
13

08

06

02

12

13

\author{
Total de \\ población \\ empadronada
}

\author{
Total de votos \\ emitidos
}

1054944

1345404

1238205

2006323

2283784

2601684

1050959

1655807

1794344

2111745

$\begin{array}{rrrrrrrr}1962 & 619491 & \text { (PRD) } & 58.7 & 317327 & \text { (UCN) } & 30.8 & 98.7 \\ 1966 & 759887 & \text { (PR) } & 56.5 & 494570 & \text { (PRD) } & 36.7 & 93.2 \\ 1970 & 653565 & \text { (PR) } & 52.8 & 252760 & \text { (MIDA) } & 20.4 & 73.2 \\ 1974 & 942726 & \text { (PR)MNJ } & 84.7 & 170693 & \text { (PDP) } & 15.3 & 100.0 \\ 1978 & 856084 & \text { (PRD) } & 51.7 & 698273 & \text { (PR) } & 42.2 & 93.9 \\ 1982 & 854868 & \text { (PRD) } & 46.7 & 669176 & \text { (PR) } & 36.6 & 83.3 \\ 1986 & 855565 & \text { (PR) } & 40.5 & 706588 & \text { (PRD) } & 33.5 & 74.0\end{array}$

Fuentes: Julio Campillo Pérez, Elecciones dominicanas, Academia Dominicana de la Historia, Santo Domingo, vol. XLIX; Darío Contreras s.f., Elecciones Dominicanas, 1962-1982: datos y análisis. Comportamiento electoral dominicano, Ed. Corripio, Santo Dormingo. También se han utilizado otros textos citados en la bibliografía. 